\title{
Características químicas de solos salino-sódicos submetidos a parcelamento da lâmina de lixiviação
}

\author{
Hugo Alberto Ruiz ${ }^{(1)}$, Regynaldo Arruda Sampaio(2), Maurício de Oliveira ${ }^{(3)}$ e Victor Hugo Alvarez Venegas ${ }^{(1)}$
}

\begin{abstract}
(1)Universidade Federal de Viçosa, Dep. de Solos, CEP 36571-000 Viçosa, MG. E-mail: hruiz@mail.ufv.br, vhav@mail.ufv.br (2)Universidade Federal de Minas Gerais, Instituto de Ciências Agrárias, Av. Osmane Barbosa, s/non, Bairro JK, Caixa Postal 135, CEP 39404-006 Montes Claros, MG. E-mail: rsampaio@nca.ufmg.br ${ }^{(3)}$ Escola Superior de Agricultura de Mossoró, Dep. de Solos, CEP 59625-620 Mossoró, RN. E-mail: mauricio@esam.br
\end{abstract}

Resumo - Em solos salino-sódicos, mesmo com a aplicação de gesso, a imediata lixiviação de sais pode promover a dispersão de argilas e problemas de impermeabilização, dificultando o processo de recuperação. O objetivo deste trabalho foi avaliar a influência do parcelamento da lâmina de lixiviação sobre diversas características químicas do extrato da pasta de saturação e do solo, em amostras de solos com características salino-sódicas. Colunas de PVC foram preenchidas com amostras de um Neossolo Flúvico de Ipanguaçu, RN; de um Neossolo Flúvico de Caicó, RN, e de um Vertissolo (V) de Mossoró, RN. Os manejos consistiram na aplicação da solução de lixiviação, com $\mathrm{CaCl}_{2}$ e $\mathrm{MgCl}_{2}$, com o volume total e parcelado em duas, quatro e seis vezes, com intervalos de 22 dias entre cada aplicação. Foram determinadas, no extrato da pasta de saturação, a condutividade elétrica e as concentrações de sódio, cálcio, magnésio e sulfatos, e no solo, os cátions trocáveis e o pH. As aplicações de gesso e de lâminas de lixiviação reduzem a porcentagem de sódio trocável e a condutividade elétrica do extrato de saturação a valores inferiores a $15 \%$ e $4 \mathrm{dS} \mathrm{m}^{-1}$, respectivamente, principalmente, quando a lâmina de lixiviação é aplicada de forma parcelada.

Termos para indexação: salinidade, gesso, recuperação de solos.

\section{Chemical characteristics of a saline-sodic soil leached with water depth parceled}

\begin{abstract}
In saline-sodic soils, even with gypsum appliance, immediate leaching of salts can promote the dispersion of clay and the impermeability of the soil, hindering soil recovery. The objective of this work was to evaluate the influence of the parceled leaching on diverse chemical characteristics of a saturated soil paste extract, in saline-sodic soil samples. Columns of PVC were filled with samples of soils Fluvent of Ipanguaçu, RN, Fluvent of Caicó, RN and Vertisol (V) of Mossoró, RN, Brazil. The management consisted in applying leaching solution, with $\mathrm{CaCl}_{2}$ and $\mathrm{MgCl}_{2}$, with the total volume and parceled in two, four and six times, with intervals of 22 days among appliances. In the saturated soil paste extract, the electrical conductivity, $\mathrm{pH}$ and concentration of sodium, calcium, magnesium and sulfates were determined. The $\mathrm{pH}$ and cations exchangeable were determined in the soil. The application of gypsum and water depth reduce the exchangeable sodium percentage and the electrical conductivity of saturated soil paste extract to values lower that $15 \%$ and $4 \mathrm{dS} \mathrm{m}^{-1}$, respectively, mainly when the water depth is applied in parcel.
\end{abstract}

Index terms: salinity, gypsum, soil reclamation.

\section{Introdução}

Os solos da Região Semi-Árida, em razão da alta taxa de evaporação e da baixa precipitação pluviométrica, apresentam, em geral, elevadas concentrações de sais solúveis. Além dos solos naturalmente halomórficos, muitos são salinizados e, ou, sodificados pelo homem, com o uso inadequado da água de irrigação (Oliveira et al., 2002). Estima-se que, no Brasil, a área total de solos afetados por sais seja superior a 4.000.000 hectares (Oliveira, 1997).
O excesso de sais solúveis leva à redução do potencial osmótico da solução do solo, dificultando a absorção de água pela planta, causando desbalanço nutricional e afetando o desenvolvimento das culturas (Carvalho \& Stamford, 1999; Dutra et al., 2000; Viana et al., 2001; Amorim et al., 2002). Quando a salinidade não é muito elevada e o sódio é o íon predominante, verificam-se toxidez nas plantas, dispersão de argilas e desestruturação dos solos, tornando-os impermeáveis (Lebron et al., 2002; McBride \& Baveye, 2002). 
O método de recuperação a ser adotado para um solo salinizado pela irrigação depende da porcentagem de sódio trocável do solo. Em porcentagem superior a 15\%, recomenda-se a aplicação de corretivos químicos, como gesso ou enxofre elementar, com o intuito de formar sulfato de sódio para lixiviação. Quando a porcentagem de sódio é inferior a 15\%, havendo uma boa drenagem da área, apenas a lavagem de sais com água de boa qualidade é suficiente (Holanda et al., 1998; Oliveira et al., 2002). Bons resultados na recuperação de solos salino-sódicos têm sido obtidos com o uso de vinhaça (Ruiz et al., 1997; Gomes et al., 2000).

Solos salino-sódicos, embora apresentem uma elevada concentração de sódio, possuem permeabilidade menos crítica do que os solos sódicos, em razão do efeito floculante dos sais solúveis. No processo de recuperação desses solos, a retirada imediata dos sais, antes mesmo que o corretivo aplicado tenha a sua maior parte solubilizada, pode levar a uma drástica redução da drenagem e, por conseguinte, inviabilizá-los para a agricultura. Sob este aspecto, a definição de práticas de manejo adequadas torna-se imprescindível para a eficácia do processo de recuperação (Oliveira et al., 2002; Freire et al., 2003).

O objetivo deste trabalho foi avaliar a influência do parcelamento da lâmina de lixiviação sobre diversas características químicas do extrato da pasta de satura- ção e do solo, em amostras de solo com características salino-sódicas.

\section{Material e Métodos}

Utilizaram-se amostras de um Neossolo Flúvico de Ipanguaçu, RN, coletadas até $20 \mathrm{~cm}$ (Ae1); de um Neossolo Flúvico de Caicó, RN, coletadas a 0-20 cm (Ae2-s) e 20-50 cm (Ae2-i), e de um Vertissolo de Mossoró (V), RN, coletadas entre 15 e $45 \mathrm{~cm}$ de profundidade (Tabela 1). A forma de amostragem e as metodologias utilizadas na caracterização dessas amostras foram descritas em Sampaio \& Ruiz (1996).

No ensaio realizado em laboratório do Departamento de Solos da Universidade Federal de Viçosa, utilizaramse colunas de PVC de $15 \mathrm{~cm}$ de diâmetro e $50 \mathrm{~cm}$ de comprimento, divididas em dois anéis inferiores de $15 \mathrm{~cm}$ e um superior de $20 \mathrm{~cm}$. As colunas foram preenchidas com solo até $45 \mathrm{~cm}$ de altura, sendo os $5 \mathrm{~cm}$ restantes utilizados para aplicação da lâmina de lixiviação. No fundo da coluna colocou-se uma tela de náilon para conter o solo e, sob esta, um recipiente para receber a solução lixiviada.

Os tratamentos corresponderam a um arranjo fatorial $4 \times 4$, quatro amostras de solo indicadas e quatro manejos da lâmina de lixiviação, em delineamento de blocos casualisados com quatro repetições. Os manejos con-

Tabela 1. Características químicas e físicas das amostras de Neossolo Flúvico de Ipanguaçu (Ae1), Neossolo Flúvico de Caicó, coletadas em camada superficial (Ae2-s) e subsuperficial (Ae2-i), e Vertissolo de Mossoró (V).

\begin{tabular}{|c|c|c|c|c|}
\hline Característica & Ae1 & Ae2-s & Ae2-i & $\mathrm{V}$ \\
\hline & \multicolumn{4}{|c|}{ Extrato da pasta de saturação } \\
\hline Condutividade elétrica $\left(\mathrm{dS} \mathrm{m}^{-1}\right)$ & 10,1 & 11,9 & 4,3 & 4,5 \\
\hline $\mathrm{Na}^{+}\left(\mathrm{mmol}_{\mathrm{c}} \mathrm{L}^{-1}\right)$ & 29,0 & 33,3 & 10,1 & 10,5 \\
\hline $\mathrm{Ca}^{2+}\left(\mathrm{mmol}_{\mathrm{c}} \mathrm{L}^{-1}\right)$ & 7,6 & 16,3 & 9,6 & 9,0 \\
\hline $\mathrm{Mg}^{2+}\left(\mathrm{mmol}_{\mathrm{c}} \mathrm{L}^{-1}\right)$ & 6,8 & 16,9 & 7,6 & 10,2 \\
\hline $\mathrm{SO}_{4}^{2-}\left(\mathrm{mmol}_{\mathrm{c}}^{\mathrm{c}} \mathrm{L}^{-1}\right)$ & 0,1 & 5,5 & 0,1 & 0,2 \\
\hline Razão de adsorção de sódio $\left(\mathrm{mmol} \mathrm{L}^{-1}\right)^{0,5}$ & 10,8 & 8,2 & 3,5 & 3,4 \\
\hline & \multicolumn{4}{|c|}{ Solo } \\
\hline pH em água, $1: 2,5$ & 6,8 & 7,8 & 7,9 & 7,7 \\
\hline $\mathrm{Na}^{+}\left(\mathrm{mmol}_{\mathrm{c}} \mathrm{kg}^{-1}\right)$ & 137 & 84 & 26 & 37 \\
\hline $\mathrm{Ca}^{2+}\left(\mathrm{mmol}_{\mathrm{c}}^{\mathrm{c}} \mathrm{kg}^{-1}\right)$ & 42 & 28 & 45 & 59 \\
\hline $\mathrm{Mg}^{2+}\left(\mathrm{mmol}_{\mathrm{c}} \mathrm{kg}^{-1}\right)$ & 54 & 48 & 56 & 103 \\
\hline Porcentagem de sódio trocável (\%) & 57 & 51 & 20 & 18 \\
\hline Necessidade de gesso $\left(\mathrm{g} \mathrm{kg}^{-1}\right)$ & 12,9 & 8,10 & 2,5 & 3,6 \\
\hline Areia grossa $\left(\mathrm{kg} \mathrm{kg}^{-1}\right)$ & 0,01 & 0,20 & 0,18 & 0,15 \\
\hline Areia fina $\left(\mathrm{kg} \mathrm{kg}^{-1}\right)$ & 0,09 & 0,49 & 0,52 & 0,20 \\
\hline Silte $\left(\mathrm{kg} \mathrm{kg}^{-1}\right)$ & 0,53 & 0,06 & 0,08 & 0,25 \\
\hline $\operatorname{Argila}\left(\mathrm{kg} \mathrm{kg}^{-1}\right)$ & 0,37 & 0,25 & 0,22 & 0,40 \\
\hline Velocidade de infiltração de água ${ }^{(1)}\left(\mathrm{mm} \mathrm{h}^{-1}\right)$ & 0,0 & 0,4 & 26,0 & 0,9 \\
\hline
\end{tabular}

${ }^{(1)}$ No período de 5 horas de determinação do teste não houve infiltração de água na amostra de solo Ae1, de forma que a velocidade de infiltração foi considerada zero. 
sistiram na aplicação da lâmina de lixiviação, equivalente a três vezes o volume de poros do sistema, de uma única vez e do mesmo volume parcelado duas, quatro e seis vezes, respectivamente, com intervalos de 22 dias entre cada aplicação. Nos intervalos, as colunas foram cobertas com plástico para diminuir as perdas de água por evaporação.

$\mathrm{O}$ corretivo utilizado foi o $\mathrm{CaSO}_{4} \cdot 2 \mathrm{H}_{2} \mathrm{O}$ p.a., numa quantidade equivalente a $100 \%$ da necessidade de gesso (Richards, 1954) para a totalidade de solo na coluna. $\mathrm{O}$ gesso foi incorporado nos $15 \mathrm{~cm}$ superficiais e o conjunto, mantido sob incubação por 43 dias. Na incubação e nas lixiviações utilizou-se uma solução de $\mathrm{CaCl}_{2}$ 5,0 $\mathrm{mmol}_{\mathrm{c}} \mathrm{L}^{-1}$ e $\mathrm{MgCl}_{2}$ 5,2 $\mathrm{mmol}_{\mathrm{c}} \mathrm{L}^{-1}$, com pH de 7,4 e condutividade elétrica de 1,2 dS m${ }^{-1}$ (Sampaio \& Ruiz, 1996).

No extrato da pasta de saturação determinou-se a condutividade elétrica (CE) e as concentrações de sódio por fotometria de emissão de chama, de cálcio e de magnésio por espectrofotometria de absorção atômica (Embrapa, 1997) e de sulfatos por turbidimetria (Chesnin \& Yien, 1950). Com os valores, calculou-se a razão de adsorção de sódio (RAS), pela expressão:

$$
\mathrm{RAS}=\frac{\mathrm{Na}^{+}}{\sqrt{\frac{\mathrm{Ca}^{2+}+\mathrm{Mg}^{2+}}{2}}},
$$

sendo as concentrações de $\mathrm{Na}^{+}, \mathrm{Ca}^{2+}$ e $\mathrm{Mg}^{2+}$ expressas em $\mathrm{mmol}_{\mathrm{c}} \mathrm{L}^{-1}$.

As análises de solo consistiram nas determinações do $\mathrm{pH}$ em água; do sódio trocável por extração com acetato de amônio $1 \mathrm{~mol} \mathrm{~L}^{-1}$ a pH 7,0 e determinação por fotometria de emissão de chama; do cálcio e do magnésio trocáveis por extração com acetato de amônio $1 \mathrm{~mol} \mathrm{~L}^{-1}$ a pH 7,0 e determinação por espectrofotometria de absorção atômica (Embrapa, 1997). Os valores dos cátions trocáveis foram estimados subtraindo das concentrações dos extratos de acetato de amônio, aquelas correspondentes ao extrato da pasta de saturação. Com os valores, calculou-se a porcentagem de sódio trocável (PST) pela expressão:

PST $=\left(\frac{\mathrm{Na}^{+}}{\mathrm{Na}^{+}+\mathrm{K}^{+}+\mathrm{Ca}^{2+}+\mathrm{Mg}^{2+}}\right) \times 100$,

sendo os teores de $\mathrm{Na}^{+}, \mathrm{K}^{+}, \mathrm{Ca}^{2+}$ e $\mathrm{Mg}^{2+}$ expressos em $\mathrm{mmol}_{\mathrm{c}} \mathrm{kg}^{-1}$.

$\mathrm{Na}$ análise de variância, a soma de quadrados para os tratamentos foi desdobrada de acordo com um es- quema de contrastes ortogonais e testados até $5 \%$ de probabilidade pelo teste F. As análises foram processadas utilizando-se o software Sistema para Análises Estatísticas - SAEG (Ribeiro Júnior, 2001).

\section{Resultados e Discussão}

A CE superou o limite de $4 \mathrm{dS} \mathrm{m}^{-1}$ na maioria dos anéis da amostra do solo Ae1 e nos anéis superiores das amostras dos solos Ae2-s e V (Tabela 2). Isso indicaria que o volume de solução aplicado foi insuficiente para a dissolução total do gesso, ou que houve uma aplicação excessiva do corretivo, de forma que a salinidade, apesar da diminuição em relação às amostras não tratadas, manteve-se em nível ainda prejudicial para as plantas (Tabela 1). Gomes et al. (2000) constataram que a manutenção de uma lâmina de $8 \mathrm{~cm}$, durante 40 dias, em solos salino-sódicos incorporados com gesso, não foram suficientes para solubilizar o corretivo e promover a sua percolação no perfil, influenciando diretamente a concentração eletrolítica da solução do solo na superfície.

$\mathrm{Na}$ amostra do solo Ae2-i, o volume de solução foi suficiente para solubilizar o gesso, retirar os sais e diminuir a $\mathrm{CE}$ até aproximadamente $1,5 \mathrm{dS} \mathrm{m}^{-1}$. Essa maior dissolução do gesso, além do volume adequado da solução de lixiviação, pode estar relacionada também à maior taxa de infiltração desta amostra, com maior desgaste das partículas do corretivo por ação da solução de lixiviação (Keren \& O'Connor, 1982). Em todas as amostras de solo, a CE foi menor nos anéis subjacentes, indicando a presença de gesso remanescente nos anéis superiores.

A amostra do solo Ae1, menos permeável, foi a de mais difícil recuperação em relação à salinidade e, conseqüentemente, à presença de sódio, conforme evidenciado pelas maiores RAS dos anéis subjacentes (Tabela 2). Nessa amostra de solo, a dose de gesso para a recuperação foi aparentemente adequada, já que a RAS do anel superior atingiu nível muito baixo e o cálcio foi elevado. É possível que o volume de solução aplicado tenha sido insuficiente para movimentar o cálcio, pois o sulfato teve uma boa distribuição entre os anéis, principalmente como sulfato de sódio, mais solúvel. O maior acúmulo de magnésio no anel superior também evidencia que o volume de solução aplicado foi insuficiente para solubilizar o gesso e promover maior movimentação de íons em profundidade.

$\mathrm{Na}$ amostra do solo Ae2-s, aparentemente, o volume total de solução aplicado foi adequado. A RAS atingiu 


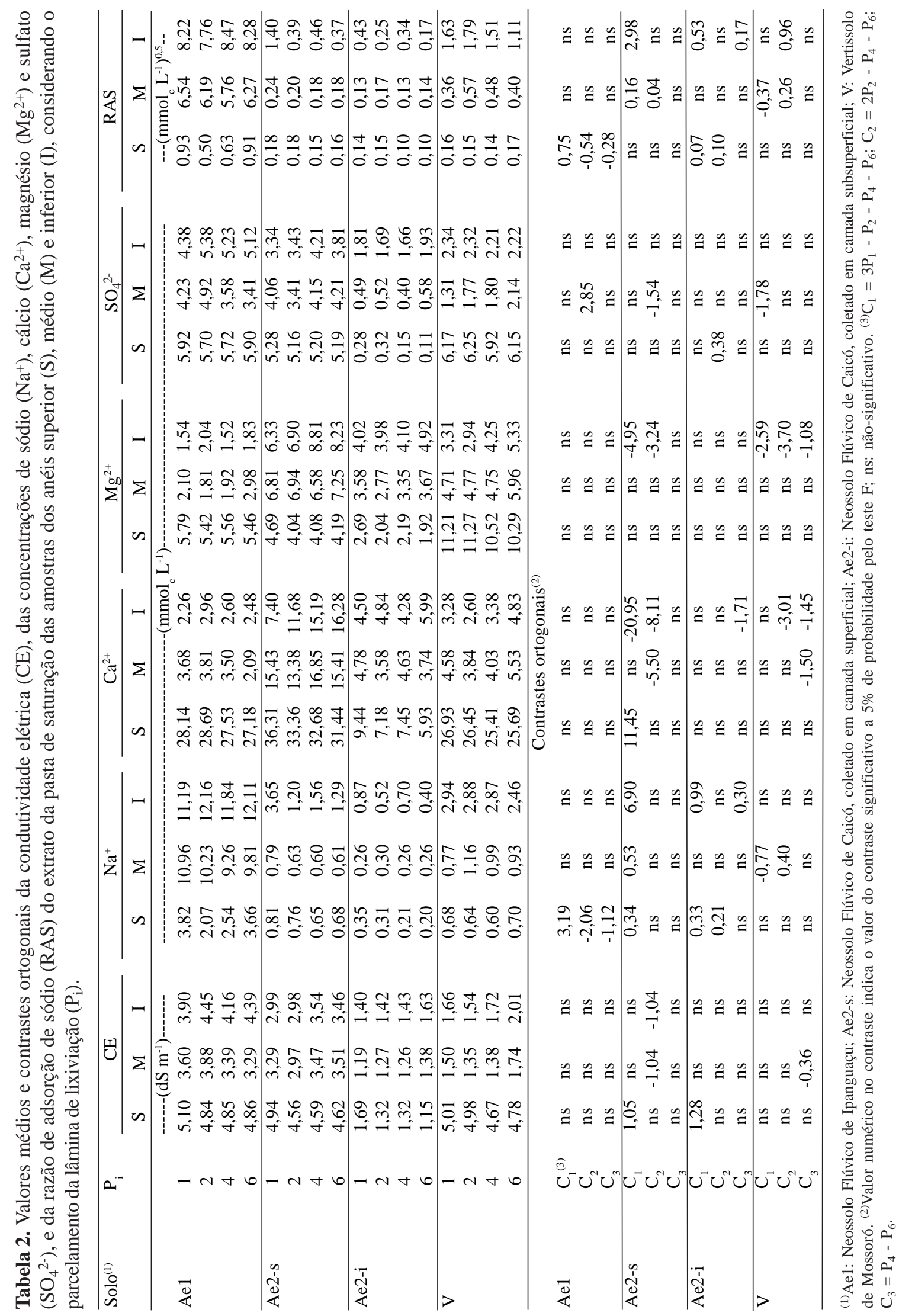


nível muito baixo, indicando que, em termos de sodicidade, a amostra de solo foi corrigida (Tabela 2). No entanto, a concentração elevada de cálcio no anel superior sugere que a dose do corretivo foi superestimada. Isso resultou numa $\mathrm{CE}$ relativamente alta até nos anéis subjacentes. Esta suposição seria também confirmada pela elevada concentração de sulfatos no anel superior e nos anéis subjacentes, indicando a translocação do gesso em razão da aplicação de um volume adequado de solução de percolação.

$\mathrm{Na}$ amostra do solo Ae2-i, verificou-se redução na CE e RAS, sugerindo que o volume total da solução e a dose do corretivo foram adequados (Tabela 2). $\mathrm{O}$ aumento do magnésio e sulfato em profundidade é uma forte evidência de que o volume de solução foi suficiente para solubilizar o gesso e lixiviar os sais.

$\mathrm{Na}$ amostra do solo $\mathrm{V}$, a CE do primeiro anel foi sensivelmente superior à dos subjacentes (Tabela 2). No mesmo anel, a RAS apresentou valores baixos e o sulfato e o cálcio mostraram valores superiores aos da amostra de solo não tratada (Tabela 1). Assim, a elevada CE foi induzida por uma aplicação excessiva de gesso, acompanhado ainda de um volume insuficiente de solução de lixiviação, pois o magnésio manteve concentrações superiores no primeiro anel, em relação aos outros dois.

Considerando o manejo da lâmina de lixiviação, a CE no anel superior das amostras dos solos Ae2-s e Ae2-i foi menor quando a lâmina foi parcelada (Tabela 2). Os maiores valores de CE na lâmina única podem estar relacionados à dissolução de maior quantidade de partículas de gesso remanescentes, pois ocorreu maior concentração de cálcio na lâmina única da amostra do solo Ae2-s. O parcelamento da lâmina manteve as condições de permeabilidade do solo, favorecendo a movimentação do cálcio em profundidade. Conforme Lebron et al. (2002) e McBride \& Baveye (2002), substituindose o sódio pelo cálcio na micela coloidal e mantendo-se uma maior concentração eletrolítica da solução do solo, a espessura da dupla camada difusa reduz-se, promovendo a floculação das argilas. Neste caso, ocorre aumento da permeabilidade do solo e lixiviação de sais.

A RAS, nos anéis subjacentes da amostra do solo Ae2-s e superior da amostra do solo Ae2-i, foi menor nas lâminas parceladas (Tabela 2). Supõe-se que o parcelamento da lâmina tenha permitido maior solubilização do gesso e deslocamento do sódio adsorvido, melhorando as condições de infiltração de água do solo e de lixiviação. Conforme Reeve \& Bower
(1960) e Reeve \& Doering (1966), a permeabilidade dos solos sódicos depende principalmente da concentração eletrolítica da solução do solo, sendo fundamental para a sua recuperação o uso de água de alta concentração eletrolítica e suas diluições sucessivas ao longo do tempo, para manter as argilas floculadas e permitir a retirada de sódio do meio.

As amostras dos solos Ae1 e V, possivelmente em face do volume insuficiente de solução aplicada, não apresentaram um comportamento definido, em relação às formas de aplicação da lâmina de lixiviação (Tabela 2).

A PST, em todas as amostras, ficou abaixo do limite de $15 \%$, prejudicial para a estrutura do solo (Tabela 3 ). Apenas a amostra do solo Ae1 apresentou valores próximos de $15 \%$ para a PST nos anéis médio e inferior. De acordo com Gheyi et al. (1995), a aplicação de gesso em solos salino-sódicos resulta em uma expressiva diminuição da PST logo no primeiro ano de sua aplicação.

$\mathrm{O}$ pH do solo, de modo geral, diminuiu no anel superior de todas as amostras de solo (Tabela 3 ), em relação aos valores das amostras não tratadas (Tabela 1). Isso seria provocado pela aplicação do gesso, em virtude da substituição do sódio adsorvido pelo cálcio do corretivo, além da precipitação dos carbonatos de sódio existentes. Segundo Oliveira (1997) e Gomes et al. (2000), a aplicação de gesso em solos sódicos tem a finalidade de transformar em sulfatos parte dos carbonatos de sódio do solo e deslocar o sódio adsorvido ao complexo de troca. Desta forma, não havendo carbonato de sódio no solo nem sódio adsorvido para sofrer hidrólise, o pH se mantém abaixo da neutralidade.

A amostra do solo Ae1 não teve uma boa recuperação do ponto de vista da sodicidade (Tabela 3). A elevada concentração de cálcio e a baixa PST no anel superior sugerem que a dose do corretivo foi adequada, porém, aparentemente faltou água para promover maior solubilização e movimentação do cálcio para as camadas subjacentes, conforme evidenciado pela PST ainda elevada. Nessa amostra de solo, nos anéis superior e médio, houve substituição de sódio e magnésio por cálcio.

A amostra do solo Ae2-s teve uma boa recuperação em termos de sodicidade (Tabela 3). A elevada concentração de cálcio no anel superior e a baixa PST para os três anéis sugerem que o volume total de solução aplicado foi adequado, promovendo a solubilização e a movimentação do cálcio na amostra de solo, mas que a dose de 


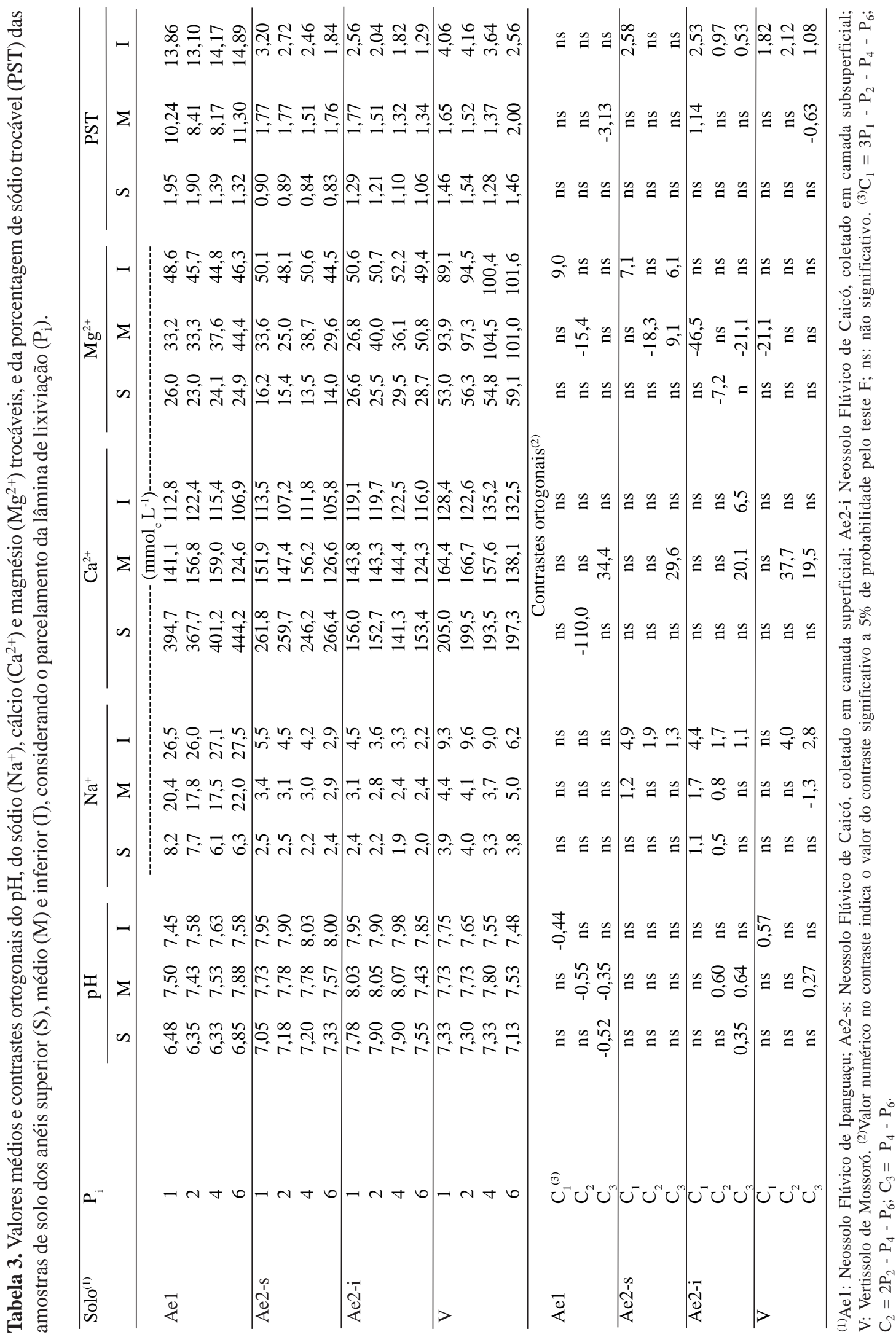


gesso incorporada ao anel superior foi excessiva. Nessa amostra de solo, o sódio foi o elemento mais substituído, seguido pelo magnésio nos anéis superior e médio.

A amostra do solo Ae2-i recuperou-se, em relação aos problemas de sódio (Tabela 3). A PST atingiu nível muito baixo e a concentração de cálcio foi aproximadamente a mesma para todos os anéis. Isso sugere que a dose de gesso e o volume de solução aplicados foram adequados para a recuperação dessa amostra de solo. $\mathrm{O} \mathrm{pH}$ alterou-se pouco em relação às amostras não tratadas e acompanhou a presença de sódio no complexo de troca. Nessa amostra de solo, depois do sódio, o magnésio foi o elemento mais substituído, em especial, nos anéis superior e médio.

A amostra do solo $\mathrm{V}$ apresentou boa recuperação do ponto de vista de sodicidade (Tabela 3). A elevada concentração de cálcio no anel superior e os baixos valores de PST, para todos os anéis, sugerem que o volume total de solução foi insuficiente e a dose de gesso aplicada, excessiva. O sódio foi o elemento que sofreu maior substituição, enquanto o magnésio foi substituído apenas no anel superior, reforçando a suposição da insuficiência de água. $\mathrm{O} \mathrm{pH}$ acompanhou a presença de sódio no complexo de troca.

A amostra do solo Ae1 não foi influenciada pelo manejo da lâmina de lixiviação, enquanto as amostras dos solos Ae2-i, Ae2-s e V foram influenciadas a maiores profundidades. As diminuições do sódio e da PST foram mais acentuadas quando a lâmina de lixiviação foi parcelada (Tabela 3). É possível que, em solos com melhor permeabilidade, a aplicação da lâmina de lixiviação de forma parcelada promova maior solubilização do gesso, sem retirar imediatamente os sais que mantém as argilas floculadas. De acordo com Gomes et al. (2000), mantendo-se uma boa permeabilidade do solo salinosódico, promove-se a livixiação de sais e principalmente a movimentação do gesso em profundidade, fundamentais para a sua recuperação.

$\mathrm{O}$ pH não mostrou comportamento bem definido, em relação ao manejo (Tabela 3). É possível que a magnitude de variação do teor de sódio ou dos sais solúveis não tenha sido suficiente para influenciar o $\mathrm{pH}$ do solo (Tabela 3).

\section{Conclusões}

1. Aplicações de gesso seguidas de lâminas de lixiviação em solos salino-sódicos reduzem a porcentagem de sódio trocável e a condutividade elétrica do ex- trato de saturação a valores inferiores a $15 \%$ e próximos de $4 \mathrm{dS} \mathrm{m}^{-1}$, respectivamente.

2. As reduções da porcentagem de sódio trocável e da condutividade elétrica do extrato de saturação são, em geral, mais acentuadas quando a lâmina de lixiviação é parcelada.

\section{Referências}

AMORIM, J.R. de A.; FERNANDES, P.D.; GHEYI, H.R.; AZEVEDO, N.C. de. Efeito da salinidade e modo de aplicação da água de irrigação no crescimento e produção de alho. Pesquisa Agropecuária Brasileira, v.37, p.167-176, 2002.

CARVALHO, F.G.; STAMFORD, N.P. Fixação do $\mathrm{N}_{2}$ em leucena (Leucaena leucocephala) em solo da região semi-árida brasileira submetido à salinização. Revista Brasileira de Ciência do Solo, v.23, p.237-243, 1999.

CHESNIN, L.; YIEN, C.H. Turbidimetric determination of available sulfates. Soil Science Society of American Proceedings, v.15, p.149-151, 1950.

DUTRA, I.; MEDEIROS, J.F. de; PORTO FILHO, F. de Q.; COSTA, M. da. C. Determinação do fator de cobertura do melão cultivado sob diferentes lâminas e salinidades da água de irrigação. Revista Brasileira de Engenharia Agrícola e Ambiental, v.4, p.146-151, 2000.

EMBRAPA. Centro Nacional de Pesquisa de Solos (Rio de Janeiro, RJ). Manual de métodos de análise de solo. 2.ed. Rio de Janeiro, 1997. 212p

FREIRE, M.B.G. dos S.; RUIZ, H.A.; RIBEIRO, M.R.; FERREIRA, P.A.; ALVAREZ VENEGAS, V.H.; FREIRE, F.J. Condutividade hidráulica de solos de Pernambuco em resposta à condutividade elétrica e RAS da água de irrigação. Revista Brasileira de Engenharia Agrícola e Ambiental, v.7, p.45-52, 2003.

GHEYI, H.R.; AZEVEDO, N.C.; BATISTA, M.A.F.; SANTOS, J.G.R. Comparação de métodos na recuperação de solo salino-sódico. Revista Brasileira de Ciência do Solo, v.19, p.173-178, 1995.

GOMES, E.M.; GHEYI, H.R.; SILVA, Ê.F. de F. e. Melhorias nas propriedades químicas de um solo salino-sódico e rendimento de arroz, sob diferentes tratamentos. Revista Brasileira de Engenharia Agrícola e Ambiental, v.4, p.355-361, 2000.

HOLANDA, J.S.; VITTI, G.C.; SALVIANO, A.A.C.; MEDEIROS, J.D.F.; AMORIM, J.R. de A. Alterações nas propriedades químicas de um solo aluvial salino-sódico decorrentes da subsolagem e do uso de condicionadores. Revista Brasileira de Ciência do Solo, v.22, p.387-394, 1998.

KEREN, R.; O'CONNOR, G.A. Gypsum dissolution and sodic soil reclamation as affected by water flow velocity. Soil Science Society of America Journal, v.46, p.726-732, 1982.

LEBRON, I.; SUAREZ, D.L.; YOSHIDA, T. Gypsum effect on the aggregate size and geometry of three sodic soils under reclamation. Soil Science Society of America Journal. v.66, p.92-98, 2002.

MCBRIDE, M.B.; BAVEYE, P. Diffuse double-layer models, longrange forces, and ordering in clay colloids. Soil Science Society of America Journal, v.66, p.1207-1217, 2002.

OLIVEIRA, L.B. de; RIBEIRO, M.R.; FERREIRA, M. da G. de V.X.; LIMA, J.F.W.F. de; MARQUES, F.A. Inferências pedológicas 
aplicadas ao perímetro irrigado de Custódia, PE. Pesquisa Agropecuária Brasileira, v.37, p.1477-1486, 2002.

OLIVEIRA, M. Gênese, classificação e extensão de solos afetados por sais. In: GHEYI, H.R.; QUEIROZ, J.E.; MEDEIROS, J.F. de (Ed.). Manejo e controle da salinidade na agricultura irrigada. Campina Grande: UFPB; SBEA, 1997. p.1-35.

REEVE, R.C.; BOWER, C.A. Use of high salt waters as a floculant and source of divalent cations for reclaiming sodic soils. Soil Science, v.90, p.139-144, 1960.

REEVE, R.C.; DOERING, E.J. The high-salt-water dilution method for reclaiming sodic soils. Soil Science Society of America Proceedings, v.30, p.498-504, 1966.

RIBEIRO JÚNIOR, J.I. Análises estatísticas no SAEG. Viçosa: UFV, 2001. 301p.
RICHARDS, L.A. (Ed.). Diagnosis and improvement of saline and alkali soils. Washington: U.S. Salinity Laboratory Staff, USDA, 1954. 160p. (Agriculture Handbook, 60).

RUIZ, H.A.; GHEYI, H.R.; ALMEIDA, M.T.; RIBEIRO, A.C. Torta de filtro e vinhaça na recuperação de um solo salino-sódico e no desenvolvimento de arroz irrigado. Revista Brasileira de Ciência do Solo, v.21, p.659-665, 1997.

SAMPAIO, R.A.; RUIZ, H.A. Características das soluções drenadas na recuperação de solos salino-sódicos com lixiviações parceladas. Revista Brasileira de Ciência do Solo, v.20, p.13-20, 1996.

VIANA, S.B.A.; FERNANDES, P.D.; GHEYI, H.R. Germinação e formação de mudas de alface em diferentes níveis de salinidade de água. Revista Brasileira de Engenharia Agrícola e Ambiental, v.5, p.259-264, 2001.

Recebido em 22 de abril de 2004 e aprovado em 20 de julho de 2004

Pesq. agropec. bras., Brasília, v.39, n.11, p.1119-1126, nov. 2004 